\title{
Design of experiments to optimize the extraction parameters of a power grade Indian coal
}

\author{
Heena Dhawan ${ }^{1} \cdot$ Sreedevi Upadhyayula $^{2}$ D. K. Sharma ${ }^{1}$
}

Received: 5 February 2018/Revised: 30 March 2018/Accepted: 29 August 2018/Published online: 8 September 2018

(C) The Author(s) 2018

\begin{abstract}
Low grade high ash coals with difficult physical washability characteristics require chemical cleaning techniques such as solvent extraction to obtain super clean coal with lower ash contents. Kedla, an Indian low grade coal has ash content around $44 \%-50 \%$ and there is a need to maximize its solvent extraction yield so as to make this power grade coal industrially useful. This paper highlights the use of definitive screening design and response surface methodology to extract the maximum organic matter from Kedla coal using ethylenediammine (EDA) and $N$-methyl pyrollidone (NMP) as solvents under mild atmospheric pressure conditions. The coal was pre-treated with acetic acid before extractions were carried out. The parameters such as the acid pre-treatment time, acid concentration, particle size, the co-solvent concentration and the solvent concentration were optimized in this paper. With this design of experiments technique about $40 \%$ of the organic matter with minimal ash (less than $2 \%$ ) content was rendered extractable unlike the already postulated designer solvent system-e, $\mathrm{N}$ system (i.e. NMP containing small amount of EDA) that uses coal to solvent ratio as 1:17 $(\mathrm{wt} / \mathrm{vol})$ and coal to co-solvent ratio as 1:1(wt/vol) thus only giving $19 \%$ extraction yield. Therefore, the present design of experiments technique helps in conserving the number of experiments for process intensification.
\end{abstract}

Keywords Coal $\cdot$ Extraction yield $\cdot$ Acid pre-treatment $\cdot$ Definitive screening design $\cdot$ Response surface methodology

\section{Introduction}

Coal is one of the most widely used fuels. It is used both as a fuel for generation of electricity and as a non- fuel for the production of value added chemicals and products (Song and Schobert 1993, 1996; Nyathi et al. 2013). Coal is also the biggest contributor to the pollution in the world. With the limitations being imposed on the $\mathrm{CO}_{2}, \mathrm{NO}_{2}$ and other harmful gases emissions into the atmosphere, it becomes all the more important to have cleaner coal combustion and utilization. Coal is basically a condensed macro-molecular

Heena Dhawan

heena.6sep@gmail.com

1 Centre for Energy Studies, Indian Institute of Technology, New Delhi 110016, India

2 Department of Chemical Engineering, Indian Institute of Technology, New Delhi 110016, India polymeric structure (Krevelen 1993; Larsen et al. 1985; Hall and Larsen 1993; Chen et al. 1998). Most of its structural constituents are aromatics, paraffinics, heteroaromatics and hydroaromatics which are held by various covalent and non-covalent interactions. These interactions are vanderwaal interactions, aromatic-aromatic, charge transfer and donor acceptor interactions between the aromatics and heterocyclic units (Haenel 1992; Nishioka and Larsen 1990; Larsen and Mohammadi 1990; Otake and Suuberg 1997; Painter et al. 1990; Rahman et al. 2017).

Indian coals are of the drift origin and the mineral matter is finely dispersed in the organic matter of these coals (Kumar and Patel 2008; Sharma and Giri 2016). High ash contents also lead to the increase in the transportation cost of coals, reduced calorific values and also results in slagging and fouling of the boilers, turbines, gasifiers etc. Therefore, it becomes important both economically and environmentally to reduce the ash contents in these coals. 
Ash content varies from $20 \%$ to $55 \%$ in Indian coals but their sulphur contents are comparatively lower $(<0.6 \%)$ (Mishra 2009). There are various methods to reduce the ash present in coals- physical, chemical and biological. However, physical techniques use less expensive resources such as water, air pulsations etc. Chemical treatments such as organo-refining and chemical leaching give better extractability of coals with much reduced ash contents (Balakrishnan et al. 2015; Meshram et al. 2015). Biological treatments use microbes to digest the mineral matter in coals (Jain and Sharma 2004). The effectiveness of each method depends upon the degree of dispersion of ash in the organic matter of coals.

Coal consists of two components-organic matter (carbonaceous matrix) and inorganic matter (mineral matter). Organic matter can be extracted using solvent extraction which leaves behind solvent refined clean coal product which has negligible ash contents (Kihong et al. 2016). The role of the solvent is to break the coal-coal interactions and replace it with the coal solvent interactions. Coal being a heterogeneous polymer shows a tendency to swell in organic solvents (Takanohashi and Iino 1995; Hernández et al. 2012; Hu et al. 1998; Mathews et al. 2015). Some solvents that have the characteristic property of donating a pair of electrons show good swelling. Mostly $\mathrm{N}$ and $\mathrm{O}$ donors are considered to be good solvents for coal extraction. Swelling gives a good idea of the extent of coal interaction with the solvent that may not necessarily always account for good extraction e.g. ethylenediammine (EDA) (Krevelen 1993). Early studies on coal extraction include the use of some basic solvents such as benzene, $\mathrm{CHCl}_{3}$, alcohol, ether, carbon disulphide as reported by Van Krevalan (1993). Coal derived solvents are also used for extraction. Coal tar and coal tar pitch were used by Honda et al. Higher boiling fractions like anthracene oils gave better extraction yields (Mishra and Sharma 1990; Elliott 1981). About $95 \%$ extraction yield has been reported by Orchin et al. with the use of boiling phenanthrene as a solvent (Krevelen 1993).

N-methyl pyrollidone (NMP) is considered to be a good solvent for coal extraction (Renganathan and Zondlo 1993; Takanohashi et al. 1996; Kirk and Othmer 2006; Dryden 1948). It is an H-bond acceptor and has good interacting ability with the aromatic structures. It is used as a solvent in oil refineries for the separation of olefins and aromatics. Renganathan and Zondlo have reported as high as 50\% extraction yields with NMP under atmospheric pressure conditions (Renganathan and Zondlo 1993; Renganathan et al. 1988). EDA has the ability to interact with the coal structure most powerfully by disrupting the $-\mathrm{OH}$ bonds. It is considered to be a good swelling solvent (Shibaoka et al. 1979; Suuberg et al. 1994; Kwak 2005).
Response surface methodology (RSM) is an analytical technique used for solving several scientific problems with minimal experimentation (Chandaliya et al. 2012). The purpose behind using this technique is to maximize the dependent output variable (response) based on the different independent input variables. A number of parameters rule a particular reaction and this methodology gives an optimum outcome of response surface corresponding to a certain reaction for maximum desirability of a particular product (Li et al. 2004; Kincl et al. 2005; Aslan and Cebeci 2007; Gunaraj and Murugan 1999; Azimi et al. 2013; Segurola et al. 1999). If $\mathrm{y}$ is the response corresponding to the $\mathrm{x}$ set of variables that govern the reaction, the relationship could be expressed as shown in Eq. (1),

$Y=f\left(x_{1} \times x_{2} \times x_{3} \times \ldots x_{m}\right)$

The parameters or the factors for a reaction could be continuous, i.e. the ones that continuously affect the course of a reaction or categorical, that do not continuously affect the course of a reaction and generally this expression is expressed in the form of a second order equation as shown in Eq. (2),

$Y=\beta_{0}+\sum \beta_{i} x_{i}+\sum \beta_{i i} x_{i}^{2}+\sum \sum \beta_{i j} x_{i} x_{j}+£$

where $x$ stands for the variables that are the input parameters of the reaction and the $\beta$ for the unknown coefficients and $£$ is the error. The $\beta$ values are calculated using the second order model. The software using these equations gives a minimum number of experiments to be performed in order to get the desired output.

The present paper highlights the use of definitive screening design (DSD) and response surface methodology (RSM) in order to maximize the extraction yield of an Indian Coal, Kedla. It involves a two step process, pretreatment with acetic-acid followed by extraction with NMP containing a small amount of EDA (co-solvent). Being a high ash coal, pre-treatment with acid enhances the extraction yield as the acid loosens the coal structure and breaks important linkages in coal making the inroads of the solvent easier inside the intermolecular spaces in coal (Masaki et al. 2005; Li et al. 2004). The work on the development of designer solvent e, $\mathrm{N}$ where coal: NMP ratio is taken as 1:17 (wt/vol) and coal:EDA ratio taken as 1:1 (wt/vol) has already been studied before in author's laboratory (Pande and Sharma 2002; Iino et al. 1988). However, presently the optimization of acid pre-treatment conditions followed by solvent extraction using design of experiments has not been reported before. Parameters taken for the study in the present paper are coal particle size, pretreatment of coal with acetic acid by varying the coal to acid ratio, acid pre-treatment time, coal to solvent ratio, \% of co-solvent in the solvent. The solvent extraction time has been optimized separately. 


\section{Materials and methods}

\subsection{Coal sample and the solvents}

Kedla coal, an Indian non-coking power grade coal was procured from NTPC (National Thermal Power Corporation), New Delhi. The proximate and ultimate analysis was performed according to IS 1350 standards. The ultimate and proximate analysis of the coal sample and the properties of the solvents used are presented in Tables 1 and 2. The acetic acid from Fischer Scientific, $N$-methyl pyrrolidone (NMP) from SRL and ethylenediamine (EDA) from LOBA chemicals were used for present extraction studies.

Equations used for the calculations:

On clean coal product basis:

Extraction yield (\% daf basis)

$$
: \frac{\text { weight }(\text { clean coal })}{1-\frac{\text { ash } \%}{100} \times \text { weight }(\text { clean coal })} \times 100 \%
$$

On loss in weight basis:

Extraction yield (\% daf basis)

$$
\begin{aligned}
& : \frac{\text { initial weight }(\text { raw coal })-\text { weight }(\text { clean coal })(100-\text { ash } \%)}{1-\frac{a s h \%}{100} \times \text { weight }(\text { clean coal })} \\
& \quad \times 100 \%
\end{aligned}
$$

Daf: dry ash free basis

\subsection{Design of experiment (DOE)}

The experiment was designed based on three levels-low, medium and high level factorial design with the variation of five main factors - the coal particle size, pre-treatment time of coal with acid, coal/acid (wt/vol) ratio, co-solvent concentration and the solvent concentration (Tables 3, 4).

\begin{tabular}{|c|c|c|c|c|c|c|c|c|}
\hline \multicolumn{3}{|c|}{ Proximate analysis } & \multicolumn{5}{|c|}{ Ultimate analysis (daf) } & \multirow{2}{*}{$\begin{array}{l}\text { Calorific value } \\
\text { (cal/g) }\end{array}$} \\
\hline$M_{\text {ad }}$ & $A_{\mathrm{d}}$ & $\mathrm{VM}_{\mathrm{daf}}$ & C & $\mathrm{H}$ & $\mathrm{N}$ & S & $\mathrm{O}^{\mathrm{a}}$ & \\
\hline 0.99 & 44.86 & 17.18 & 52.9 & 3.3 & 1.1 & 0.5 & 42.2 & 4209 \\
\hline
\end{tabular}

Table 1 Proximate and ultimate analysis (wt \%) (on air dried basis) of Kedla coal

${ }^{\mathrm{a}}$ By difference
Then based upon the results for those five parameters, a three level factorial design using RSM methodology was used for further optimization (Tables 5, 6).

Particle size is one of the most important parameters for coal extraction studies as coal extraction largely depends on the lump size that is fed into the reactors. Lesser the particle size better is the interaction of coal with the solvents which ultimately affects the extraction yields. Therefore, the upper limit for particle size was chosen as $+250 \mu \mathrm{m}$ and lower limit as $-125 \mu \mathrm{m}$ for the present study. The coal to acid (wt/vol) ratio was taken as 1:10-1:20. This range was of coal amount was found to be suitable for the effective interaction and pre-treatment with acetic acid. Moreover, the acid recovered after filtration can be reused. The time of acid pre-treatment was taken from $30 \mathrm{~min}$ (low level) to $120 \mathrm{~min}$ (high level) as after the pre-treatment with the acetic acid, extraction for $2 \mathrm{~h}$ with the solvents (NMP and EDA) was performed. The coal to solvent ratio was kept between 1:10 and 1:20 as in between these limits, the fluidity of the coal-solvent mixture is maintained. Also with excessive use of solvents, their recovery becomes difficult and the process becomes more uneconomical. $10 \%-15 \%$ of co-solvent EDA of total solvent concentration ( $\mathrm{vol} / \mathrm{vol})$ was found enough to effectively break important linkages such as H-bonds in coal in order to make inroads for the main solvent NMP into the condensed coal structure (Pande and Sharma 2002).

Another important parameter that was optimized separately was the time of the solvent (NMP-EDA) extraction. It was kept for $2 \mathrm{~h}$ for each run and was optimized separately, which has been explained later in the text. Based on the responses of the definitive screening design, a three level continuous factor based RSM experimental design was developed as presented in Table 6.

\subsection{Experimental procedure}

For each run of the DSD experiment, Kedla coal ( $2 \mathrm{~g})$ was taken in a $250 \mathrm{~mL}$ round bottomed flask along with the acetic acid and refluxed for the desired time as shown in Tables 3 and 4 . The solution was then filtered and the coal dried overnight in oven at $105^{\circ} \mathrm{C}$. This coal was used for refluxing in a $250 \mathrm{~mL}$ round bottomed flask under milder ambient pressure conditions with the given concentration

Table 2 Properties of the two main solvents, NMP and EDA

\begin{tabular}{lllllll}
\hline Solvent & $T_{\mathrm{b}}\left({ }^{\circ} \mathrm{C}\right)$ & $\rho\left(20^{\circ} \mathrm{C}\right)$ & $\eta\left(\mathrm{N} / \mathrm{m}^{2}\right)$ & $\mu(\mathrm{D})$ & $\mathrm{DN}$ & $\delta\left(\mathrm{jcm}{ }^{-3}\right)^{1 / 2}$ \\
\hline$N$-methyl pyrrolidone & 202 & 1.028 & 1.67 & 4.09 & 27.3 & 22.9 \\
Ethylenediamine & 118 & 0.903 & 1.54 & 1.99 & 55.0 & 25.3 \\
\hline
\end{tabular}

$T_{\mathrm{b}}$, boiling point; $\rho$, specific gravity; $\eta$, viscosity; $\mu$, dipole moment; DN, donor number; $\delta$, solubility parameter 
Table 3 Three level factorial design for optimization of five parameters

\begin{tabular}{llllll}
\hline Levels & Particle size $(\mu \mathrm{m})$ & $\begin{array}{l}\text { Time of acid } \\
\text { pre-treatment }(\mathrm{min})\end{array}$ & $\begin{array}{l}\text { Coal/acid } \\
\text { ratio(wt/vol) }\end{array}$ & $\begin{array}{l}\text { \% Co-solvent (EDA) } \\
\text { in solvent (vol\%) }\end{array}$ & $\begin{array}{l}\text { Coal/solvent (NMP) } \\
\text { ratio (wt/vol) }\end{array}$ \\
\hline Low level $(-1)$ & -125 & 30 & $1: 10$ & 10 & $1: 10$ \\
Average (0) & $125-250$ & 60 & $1: 15$ & 12.5 & $1: 15$ \\
High level (1) & +250 & 120 & $1: 20$ & 15 & $1: 20$ \\
\hline
\end{tabular}

Table 413 Run definitive screening design (DSD) for optimization of five parameters

\begin{tabular}{|c|c|c|c|c|c|c|}
\hline $\begin{array}{l}\text { Run } \\
\text { no. }\end{array}$ & $\begin{array}{l}\text { Particle } \\
\text { size }(\mu \mathrm{m})\end{array}$ & $\begin{array}{l}\text { Time of pre- } \\
\text { treatment (min) }\end{array}$ & $\begin{array}{l}\text { Coal/acid ratio } \\
\text { (wt/vol) }\end{array}$ & $\begin{array}{l}\% \text { Co-solvent (EDA) in solvent } \\
(\mathrm{NMP}+\mathrm{EDA})(\mathrm{vol} \%)\end{array}$ & $\begin{array}{l}\text { Coal/solvent (NMP) } \\
\text { ratio (wt/vol) }\end{array}$ & $\begin{array}{l}\text { Response } \\
\text { (Y) (extraction yield } \\
\%)\end{array}$ \\
\hline 1 & 1 & 0 & -1 & 1 & 1 & 23.18 \\
\hline 2 & 1 & -1 & 0 & -1 & 1 & 19.01 \\
\hline 3 & -1 & -1 & -1 & 1 & 0 & 27.28 \\
\hline 4 & -1 & -1 & 1 & 0 & 1 & 37.95 \\
\hline 5 & 1 & 1 & 1 & -1 & 0 & 22.74 \\
\hline 6 & -1 & 1 & -1 & -1 & 1 & 30.56 \\
\hline 7 & 1 & -1 & 1 & 1 & -1 & 18.25 \\
\hline 8 & 0 & 1 & 1 & 1 & 1 & 27.63 \\
\hline 9 & -1 & 1 & 0 & 1 & -1 & 18.35 \\
\hline 10 & 1 & 1 & -1 & 0 & -1 & 23.66 \\
\hline 11 & -1 & 0 & 1 & -1 & -1 & 34.73 \\
\hline 12 & 0 & 0 & 0 & 0 & 0 & 12.54 \\
\hline 13 & 0 & -1 & -1 & -1 & -1 & 28.02 \\
\hline
\end{tabular}

Table 5 Three levels for the factorial design (for RSM methodology—-further optimization of extraction parameters)

\begin{tabular}{llll}
\hline \multicolumn{1}{c}{ Item } & Particle size $(\mu \mathrm{m})$ & $\%$ Co-solvent (EDA) in solvent (NMP + EDA) (vol\%) & Coal/solvent (NMP) ratio (wt/vol) \\
\hline Low level $(-1)$ & -125 & 10 & $1: 10$ \\
Average $(0)$ & $125-250$ & 12.5 & $1: 15$ \\
High level (1) & +250 & 15 & $1: 20$ \\
\hline
\end{tabular}

in Table 4 of the solvent-NMP and co-solvent EDA for $2 \mathrm{~h}$. The coal solvent mixture was cooled and then filtered. The filtrate was distilled-off to remove the excess solvent and the clean coal product was precipitated using water as the anti-solvent. The recovered solvent can be reused. The residual coal and the clean coal product were washed with $2 \%-5 \%$ aq. $\mathrm{HCl}$ solution and water. Both were then dried overnight in an oven at $100{ }^{\circ} \mathrm{C}$ and weighed to obtain the extraction yield.

For each run of the RSM experiment, the coal sample $(2 \mathrm{~g})$ of the particle size, as mentioned in Table 6, was taken in a round bottomed flask and refluxed for about an hour with $30 \mathrm{~mL}$ (Based on DSD responses) of acetic acid (Li et al. 2004). The coal-acid mixture was cooled and filtered. The acid treated coal was then dried overnight in an oven at about $100{ }^{\circ} \mathrm{C}$ and weighed. This was then refluxed under milder ambient pressure conditions with the amount of the co-solvent (EDA) and the solvent (NMP) as shown in Table 6 for about $2 \mathrm{~h}$. Following the same procedure as already mentioned, the extraction yield was calculated both on clean coal product basis and on loss in weight basis.

\section{Results and discussion}

\subsection{Extraction time}

In each run, the solvent (NMP-EDA) extraction time has been taken as $2 \mathrm{~h}$. Another set of experiments with the variation in the experimental time and keeping the coal to EDA (1:1) (wt/vol) and coal to solvent (1:17) (wt/vol) ratio fixed were carried out. The graph obtained for the extraction yield (\%) versus time (h) has been shown in Fig. 1.

About $26.2 \%$ of the extraction yield could be obtained in just first $2 \mathrm{~h}$ of extraction which is about $60 \%$ of the total 
Table 615 Runs experimental set up obtained using response surface methodology-Box Behnken design

\begin{tabular}{|c|c|c|c|c|c|c|}
\hline $\begin{array}{l}\text { S. } \\
\text { no. }\end{array}$ & $\begin{array}{l}\text { Particle } \\
\text { size }\end{array}$ & $\begin{array}{l}\% \text { Co-solvent }(\mathrm{A}) \text { in } \\
\text { solvent }(\mathrm{A}+\mathrm{B})\end{array}$ & $\begin{array}{l}\text { Coal/solvent } \\
(\mathrm{A}+\mathrm{B}) \text { ratio }\end{array}$ & $\begin{array}{l}\text { Experimental value- } \\
\text { particle size }(\mu \mathrm{m})\end{array}$ & $\begin{array}{l}\text { Experimental value-co- } \\
\text { solvent (mL) (for } 2 \mathrm{~g} \text { coal) }\end{array}$ & $\begin{array}{l}\text { Experimental value-solvent } \\
\text { (mL) (for } 2 \mathrm{~g} \text { coal) }\end{array}$ \\
\hline 1 & 0 & -1 & -1 & $125-250$ & 3.75 & 26.25 \\
\hline 2 & 1 & -1 & 0 & -125 & 3 & 27 \\
\hline 3 & 1 & 1 & 0 & $125-250$ & 3 & 17 \\
\hline 4 & 0 & -1 & 1 & $125-250$ & 6 & 34 \\
\hline 5 & 1 & 0 & -1 & $125-250$ & 2 & 18 \\
\hline 6 & 0 & 1 & 1 & +250 & 5 & 35 \\
\hline 7 & -1 & 0 & 1 & -125 & 4.5 & 25.5 \\
\hline 8 & 0 & 0 & 0 & +250 & 2.5 & 17.5 \\
\hline 9 & 1 & 0 & 1 & -125 & 2.5 & 17.5 \\
\hline 10 & 0 & 0 & 0 & +250 & 4.5 & 25.5 \\
\hline 11 & 0 & 1 & -1 & $125-250$ & 4 & 36 \\
\hline 12 & -1 & -1 & 0 & $125-250$ & 3.75 & 26.25 \\
\hline 13 & -1 & 0 & -1 & +250 & 3 & 27 \\
\hline 14 & 0 & 0 & 0 & $125-250$ & 3.75 & 26.25 \\
\hline 15 & -1 & 1 & 0 & -125 & 5 & 35 \\
\hline
\end{tabular}

possible exhaustive extraction yield of $45 \%$ (obtained in $24 \mathrm{~h}$ ). Therefore, keeping in mind, the added extra consumption of resources (electricity, equipment etc.) and avoiding much complexity in extraction conditions, the appropriate extraction time in each NMP-EDA run was taken as $2 \mathrm{~h}$.

\subsection{Screening and interpretation of data}

Minitab(18) and JMP(11.0) were used to generate the runs and for the interpretation of the responses. The screening for the DSD for the optimization of five parameters gave relevant input that the significance of particle size, \% cosolvent concentration and the coal/solvent concentration was much more than the other two parameters (acid pretreatment time and coal to acid ratio) for the extraction. Their extent of influence was measured by their $p$-values

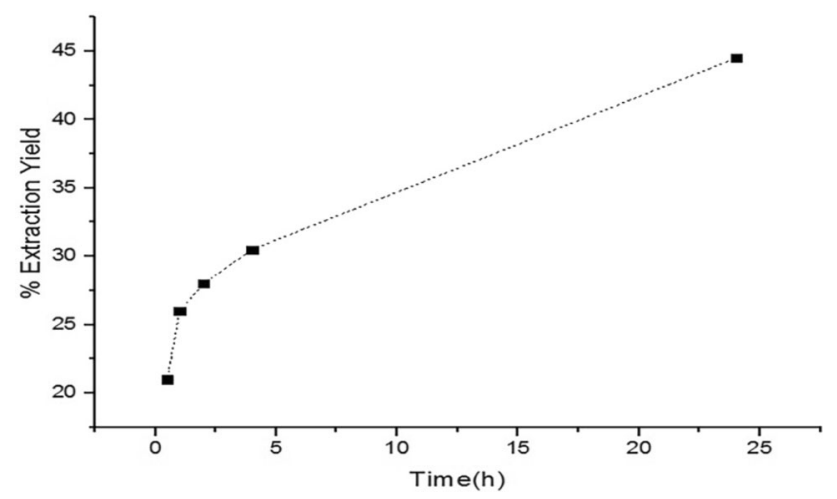

Fig. 1 A plot of extraction yield (\%) versus time to optimize the extraction time of Kedla Coal and $t$-ratios. The particle size shows a larger negative t-ratio value followed by the $\%$ co-solvent and then a positive t-ratio for the solvent concentration (Fig. 2). The effect of acetic acid pre-treatment and time of acid pretreatment were not found to be as high as compared to the other parameters because acetic acid selectively acts on $\mathrm{Ca}$ and $\mathrm{Mg}$ cations in coal that are bridged through oxygen functional groups especially in low-rank coals (Masaki et al. 2005; Li et al. 2004). Its selectivity to act upon the certain cations in coal makes it relatively less significant to drastically influence the extraction yields. Moreover, NMP acts upon aromatic rings and breaks the strong cross-linkages in the coal macromolecular structure and EDA cleaves $\mathrm{H}$-bonds in coals thereby promoting the action of the main solvent NMP (Pande and Sharma 2002). The particle size provides more surface area for the action of these solvents. Thus these three parameters-particle size, \% co-solvent (EDA) concentration and the coal/solvent (NMP) concentration were used again for response surface methodology (RSM) in order to further maximize the extractability.

The responses (extraction yields) on clean coal product basis were found to be in good agreement with the loss in weight basis with a standard error of about $2 \%-3 \%$. Using JMP (11.0), the effect of the three scaled down parametersparticle size, \% co-solvent in solvent $(\mathrm{A} / \mathrm{A}+\mathrm{B})$ and coal/solvent (Coal/A $+\mathrm{B})$ ratio were studied (Table 7). The responses well fitted with the second order equation obtained with the RSM-Box Behnken method and the $R^{2}$ value (ratio of the sum of squares of the predicted responses to the sum of squares of the observed responses) was also found to be 0.966 (Table 8 ) which verified the good strength of model fitting. Final experimental 


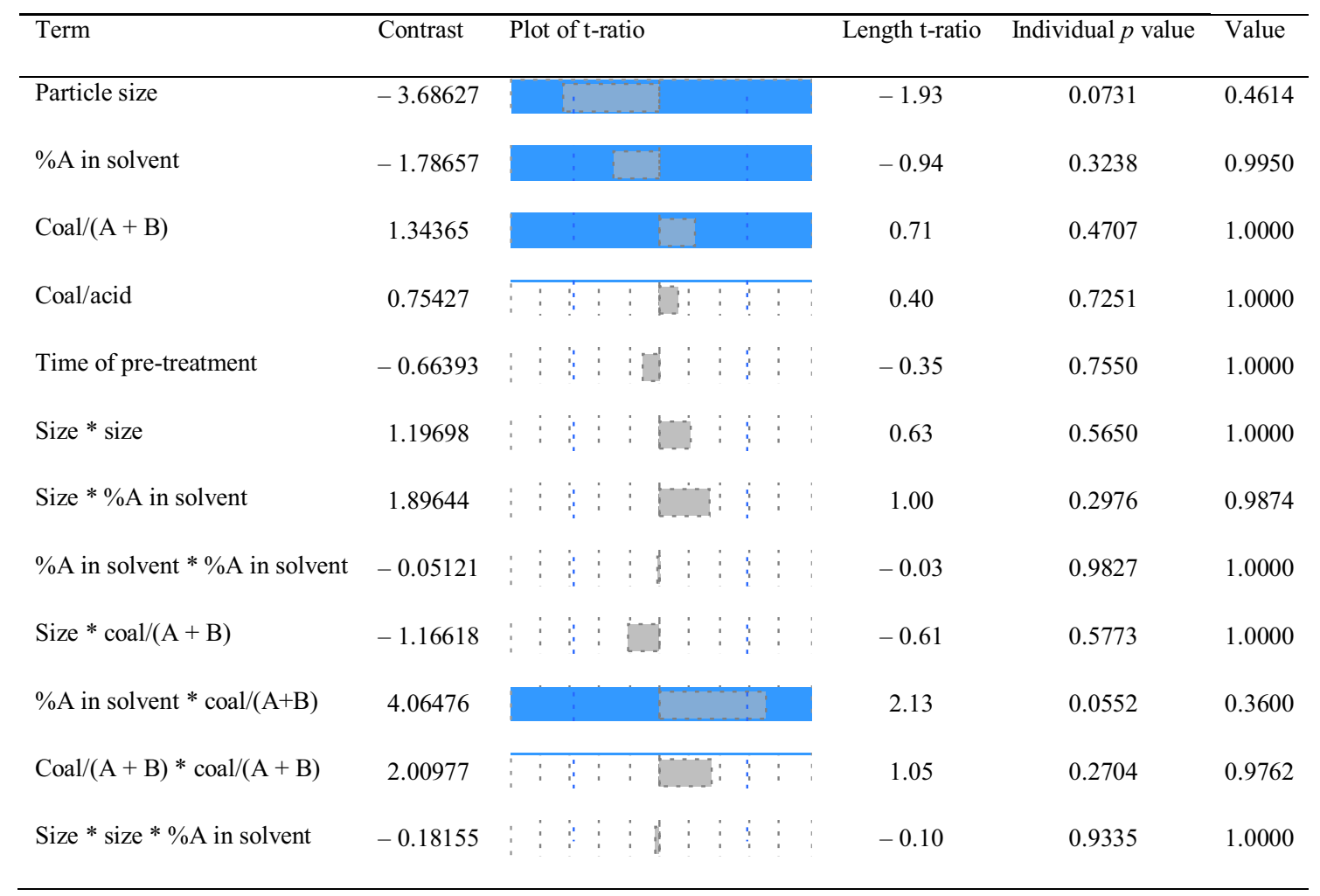

Fig. 2 Screening for five parameters of the definitive screening design (DSD). A: co-solvent (EDA) concentration, A + B: total solvent concentration (NMP + EDA)

Table 7 The responses obtained for the design of the experiments RSM

\begin{tabular}{lcccc}
\hline S. no. & Particle size $(\mu \mathrm{m})$ & $\begin{array}{l}\text { \% Co-solvent }(\mathrm{A}) \text { in } \\
\text { solvent }(\mathrm{A}+\mathrm{B})(\mathrm{vol} \%)\end{array}$ & $\begin{array}{l}\text { Coal/solvent }(\mathrm{A}+\mathrm{B}) \\
\text { ratio }(\mathrm{wt} / \mathrm{vol})\end{array}$ & $\begin{array}{l}\text { Response }(\mathrm{Y}) \text { extraction yield }(\%) \\
\text { (on clean coal product basis) }\end{array}$ \\
\hline 1 & 0 & -1 & -1 & 25.6 \\
2 & 1 & -1 & 0 & 13.3 \\
3 & 1 & 1 & 0 & 11.2 \\
4 & 0 & -1 & 1 & 22.1 \\
5 & 1 & 0 & -1 & 15.4 \\
6 & 0 & 1 & 1 & 26.5 \\
7 & -1 & 0 & 1 & 37.3 \\
8 & 0 & 0 & 0 & 19.4 \\
9 & 1 & 0 & 0 & 18.5 \\
10 & 0 & 0 & -1 & 18.1 \\
11 & 0 & 1 & 0 & 24.8 \\
12 & -1 & -1 & -1 & 36.2 \\
13 & -1 & 0 & 0 & 34.0 \\
14 & 0 & 0 & 0 & 18.2 \\
15 & -1 & 1 & & 36.0
\end{tabular}

validation was carried out to obtain the maximum extraction yield according the parameter values given by the prediction profiler (Table 9 and Fig. 3).

The most probable parameter values to obtain the maximum extraction yield were predicted by JMP (11.0) an
Minitab(18) were : $-125 \mu \mathrm{m}$ (particle size), 15\% co-solvent (EDA) of total solvent (NMP) concentration and coal to solvent (NMP) ratio as 1:20 (wt/vol). The predicted extraction yield according to JMP(11.0) was 39.5\% which was validated through experimentation that gave the 
Table 8 Summary of fit

\begin{tabular}{ll}
\hline$R^{2}$ & 0.966148 \\
$R^{2}$ Adj & 0.763036 \\
Root mean square error & 4.186088 \\
Mean of response & 24.17333 \\
\hline
\end{tabular}

extraction yields of $40.8 \%$ on clean coal basis and $39.9 \%$ on residual coal basis. This final run was repeated three times and the average extraction yields based on clean coal product basis and loss in weight basis have been presented in Table 9. Figure 4 shows the difference in the predicted values and the experimental values of extraction yields (Table 10).

The parameter values that are obtained through the profiler were found to be for factor $X_{1}$ (particle size), $X_{2}$ (co-solvent concentration) and $X_{3}$ (solvent concentration) are correspondingly of the levels $-1,1,1$ respectively, i.e. minimizing the particle size and maximizing the co-solvent to solvent ratio and the solvent concentration gives the maximum output i.e. an extraction yield of about 39.5\% (Table 9) which has been validated through experimentation as discussed earlier in the text. The values of the intercepts show the influence of each parameter individually and the interaction profilers show the influence of second order interactions among the parameters. The intercepts show that the influence of the particle size is the highest with a negative maximum intercept and the t-value depicting the increase in output with subsequent decrease in particle size. The impact of the co-solvent and the solvent is not as significant as compared to that of the particle size. The second order interactions show more impact on the extraction yield than the third order. The p-value for particle size factor was found to be closest to 1 further confirming how influential the factor is on the extraction yield and the next influential factor with the second order value is the solvent concentration that shows the relevance of the nature of the solvent for extraction. The measurement (least or highest) of the p-value is indicative of the significance of that factor. The p-value for the particle size $(\gg 0.05)$ (Fig. 2) shows the much higher significance of this parameter on the overall extraction yield (significance of $95 \%$ confidence interval $>0.05$ ). Using the above

Table 9 Final validation for maximum extraction yield

\begin{tabular}{lllllll}
\hline $\begin{array}{l}\text { Final } \\
\text { experimental } \\
\text { validation }\end{array}$ & $\begin{array}{l}\text { Particle } \\
\text { size }(\mu \mathrm{m})\end{array}$ & $\begin{array}{l}\text { \% Co-solvent } \\
\text { in solvent }\end{array}$ & $\begin{array}{l}\text { Coal/solvent } \\
\text { ratio (wt/vol) }\end{array}$ & $\begin{array}{l}\text { Predicted } \\
\text { value }(\%)\end{array}$ & $\begin{array}{l}\text { Experimental value (clean } \\
\text { coal product basis) }(\%)\end{array}$ & $\begin{array}{l}\text { Experimental value (loss in } \\
\text { weight basis) }(\%)\end{array}$ \\
\hline 16 & -1 & $1(15 \%)$ & $1(1: 20)$ & 39.5 & 40.87 & 39.98 \\
& $(-125)$ & & & \\
\hline
\end{tabular}

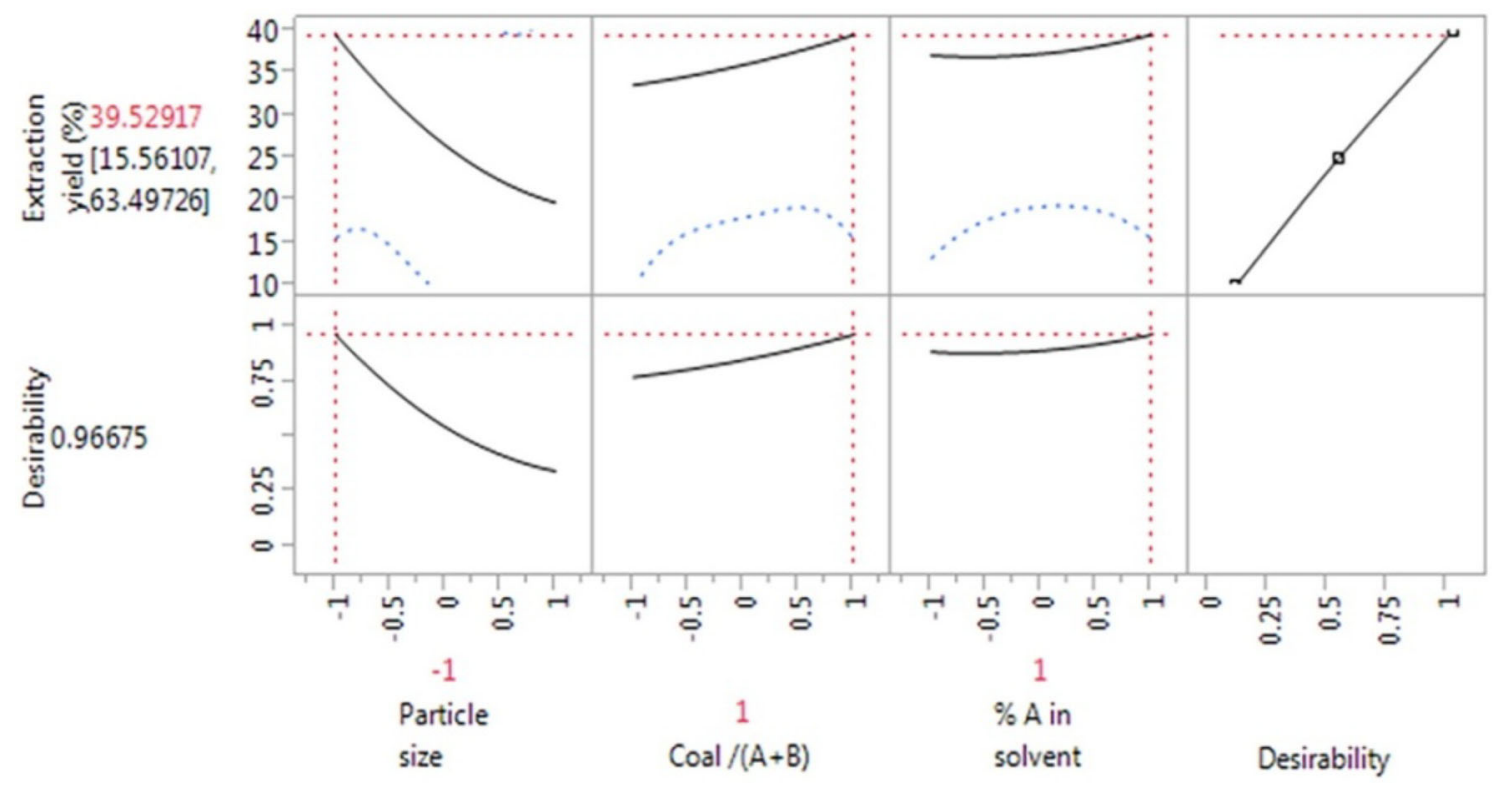

Fig. 3 Prediction profiler showing the variation of extraction yields with different parameters and the maximum desirability value 


\section{Scatterplot of extraction yield (\%) (experimental) vs extraction yield (\%) (predicted)}

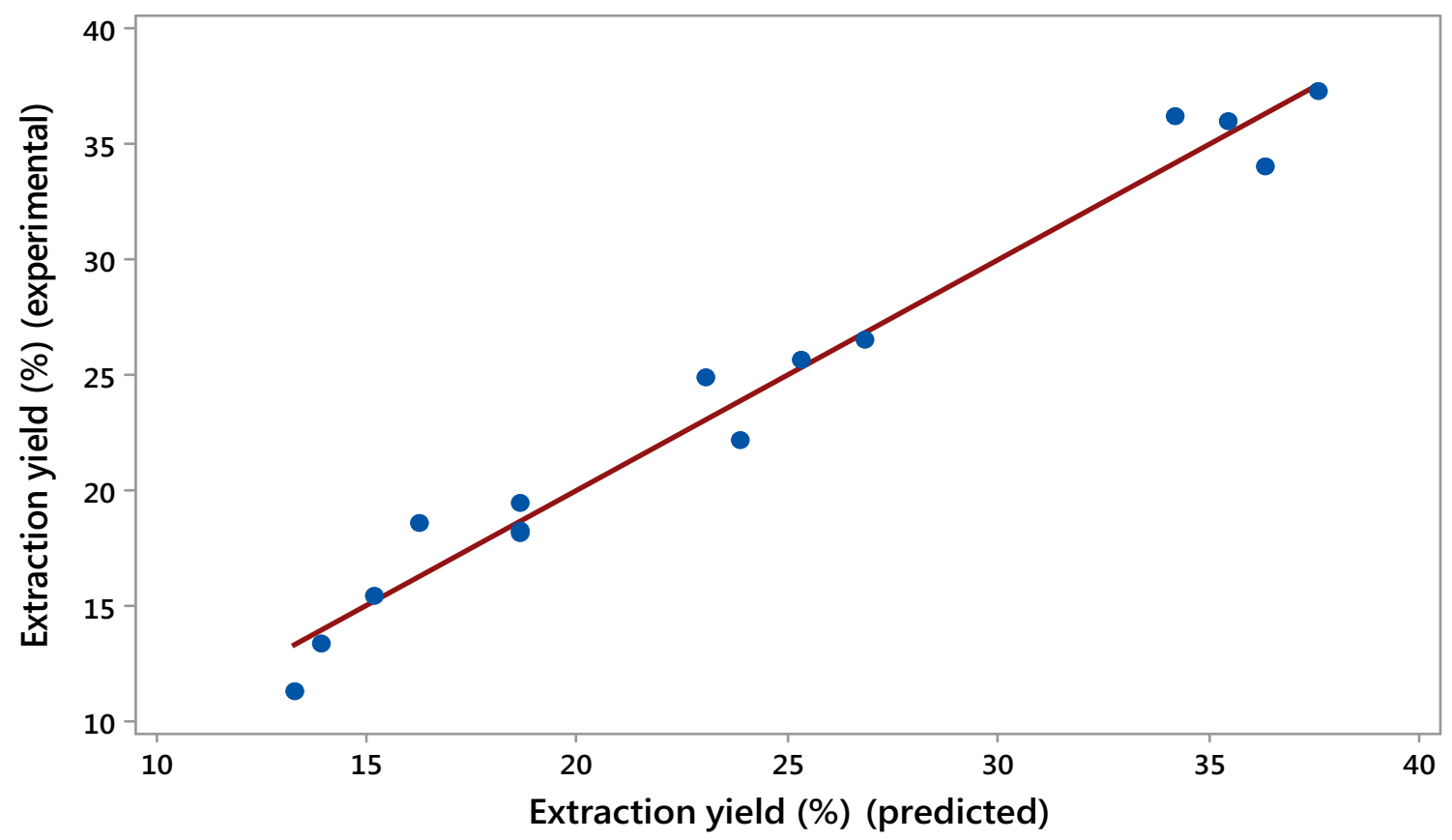

Fig. 4 Plot of difference showing the variation in the extraction yield obtained experimentally and the predicted values through the RSM technique

Table 10 Variation in experimental and the predicted values

\begin{tabular}{lllc}
\hline $\begin{array}{l}\text { Run. } \\
\text { no. }\end{array}$ & $\begin{array}{l}\text { Experimental extraction } \\
\text { yield (\%) (on clean coal } \\
\text { product basis) }\end{array}$ & $\begin{array}{l}\text { Predicted } \\
\text { extraction } \\
\text { yield }(\%)\end{array}$ & $\begin{array}{l}\text { Residual } \\
\text { extraction } \\
\text { yield }(\%)\end{array}$ \\
\hline 1 & 19.4 & 18.56 & 0.84 \\
2 & 15.4 & 15.13 & 0.27 \\
3 & 36.2 & 34.17 & 2.03 \\
4 & 18.1 & 18.56 & -0.46 \\
5 & 26.5 & 26.78 & 0.28 \\
6 & 18.2 & 18.56 & -0.36 \\
7 & 37.3 & 37.56 & -0.26 \\
8 & 25.6 & 25.31 & 0.30 \\
9 & 34.0 & 36.31 & -2.31 \\
10 & 18.5 & 16.18 & 2.32 \\
11 & 24.8 & 23.03 & 1.77 \\
12 & 36.0 & 35.45 & 0.55 \\
13 & 13.3 & 13.85 & -0.55 \\
14 & 11.2 & 13.22 & -2.02 \\
15 & 22.1 & 23.86 & -1.76 \\
\hline
\end{tabular}

values, the following equation for the output (extraction yield) based on intercept values (Table 11) has been predicted that helps to study the influence of each individual parameter on the extraction yield:

$$
\begin{aligned}
Y= & 20.5666-11.925 \times \text { particle size }-0.45 \\
& \times \text { Coal } /(\mathrm{A}+\mathrm{B}) \\
& + \text { particle size } \times[\text { particle size } \times 2.5791] \\
& + \text { particle size } \times[\text { Coal } /(\mathrm{A}+\mathrm{B}) \times-0.05] \\
& + \text { Coal } /(\mathrm{A}+\mathrm{B})[\mathrm{Coal} /(\mathrm{A}+\mathrm{B}) \times 3.4541] \\
& + \text { particle size } \times[\% \mathrm{~A} \text { in solvent } \times-0.475] \\
& + \text { Coal } /(\mathrm{A}+\mathrm{B}) \times[\% \mathrm{~A} \text { in solvent } \times 1.3] \\
& +\% \mathrm{~A} \text { in solvent } \times[\% \mathrm{~A} \text { in solvent } \times 1.0291] \\
& + \text { particle size } \times[\text { particle size } \times[\mathrm{Coal} /(\mathrm{A}+\mathrm{B}) \times 2.05]] \\
& + \text { particle size } \times[\mathrm{Coal} /(A+B) \\
& \times[\text { Coal } /(\mathrm{A}+\mathrm{B}) 2.575]]+ \text { particle size } \\
& \times[\text { particle size } \times[\% \mathrm{~A} \text { in solvent } \times-1.475]]
\end{aligned}
$$

\subsection{Contour plots}

Figures 5, 6 and 7 show the contour plots and the response surface interactions between the different parameters. The response surface plots between the particle size and the \% co-solvent in solvent (Fig. 7a) and particle size and coal to solvent ratio (Fig. 7b) are largely elliptical while the plot between the solvent and the co-solvent concentration (Fig. 7c) is parabolic in nature. It shows the major role played by the coal particle size on the extraction yield as it has already been discussed earlier by its intercept values. With the reduction in particle size, the interaction of the coal with the solvents increases. Giri and Sharma (2000) have reported mass transfer effects in the solvent extraction 
Contour Plot of Extraction yield (\%) vs C,B
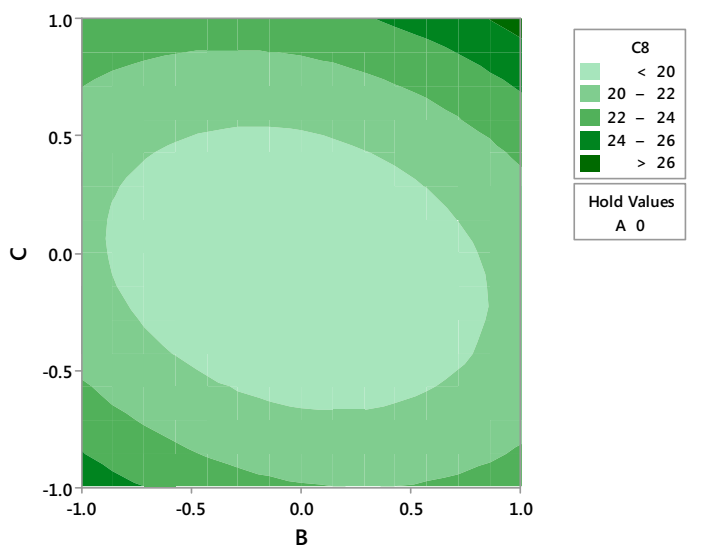

Contour Plot of Extraction yield (\%) vs C, A
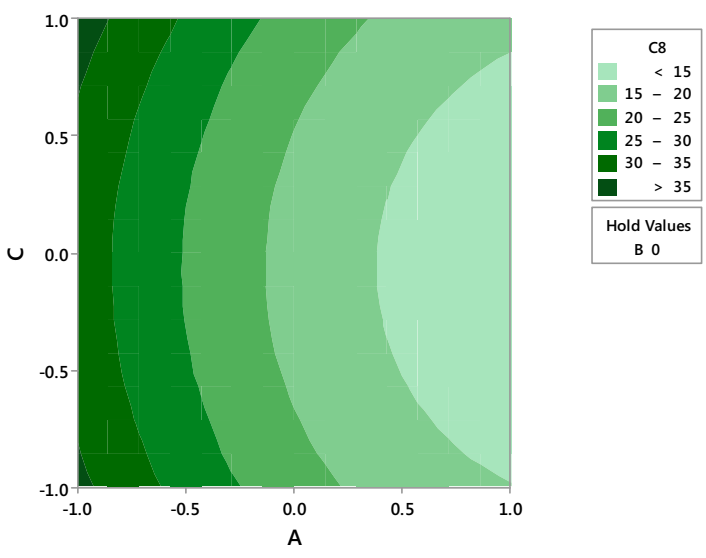

Contour Plot of Extraction yield (\%) vs B, A

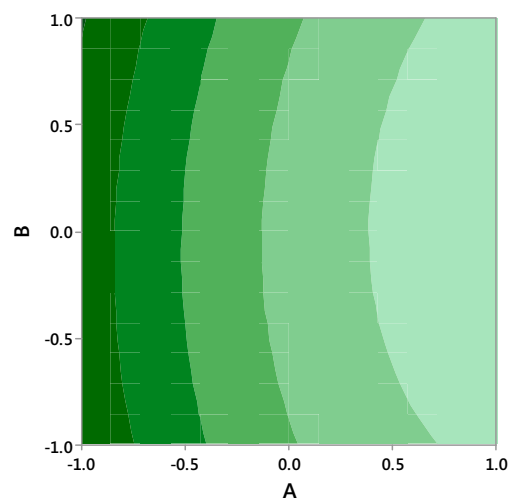

Fig. 5 Contour plots of $\%$ extraction yield versus different parameters (A: particle size, B: \% co-solvent in solvent, C: total amount of co-solvent + solvent)

of coals. With more surface area available, the solvents NMP and EDA disrupt more coal-coal interactions by breaking H-bonds, $\pi-\pi$ interactions, vanderwaal forces and charge transfer interactions. NMP then better interacts with the coal macromolecular structure especially aromatic rings thereby resulting in enhanced extraction (Pande and Sharma 2002; Iino et al. 1988).
Table 11 Screening for $Y \quad(\%$ Extraction yield $)$ by $\mathrm{RSM}$ Methodology

\begin{tabular}{|c|c|c|c|c|}
\hline Term & $\begin{array}{l}\text { Scaled } \\
\text { estimate }\end{array}$ & $\begin{array}{l}\text { Std. } \\
\text { error }\end{array}$ & $t$ ratio & Prob $>\mathrm{t}$ \\
\hline Intercept & 20.56 & 2.41 & 8.51 & 0.0135 \\
\hline Particle size & -11.92 & 2.09 & -5.70 & 0.0295 \\
\hline $\operatorname{Coal} /(\mathrm{A}+\mathrm{B})$ & -0.45 & 2.09 & -0.21 & 0.8497 \\
\hline$\% \mathrm{~A}$ in solvent & 0.9 & 2.09 & 0.43 & 0.7091 \\
\hline Particle size $*$ particle size & 2.57 & 2.17 & 1.18 & 0.3581 \\
\hline $\begin{array}{l}\text { Particle size * coal } / \\
\quad(\mathrm{A}+\mathrm{B})\end{array}$ & -0.05 & 2.09 & -0.02 & 0.9831 \\
\hline $\begin{array}{l}\mathrm{Coal} /(\mathrm{A}+\mathrm{B}) * \mathrm{coal} / \\
\quad(\mathrm{A}+\mathrm{B})\end{array}$ & 3.15 & 2.178 & 1.45 & 0.2846 \\
\hline $\begin{array}{l}\text { Particle size *\% } \mathrm{A} \text { in } \\
\text { solvent }\end{array}$ & -0.47 & 2.09 & -0.23 & 0.8416 \\
\hline $\begin{array}{l}\mathrm{Coal} /(\mathrm{A}+\mathrm{B}) * \% \mathrm{~A} \text { in } \\
\text { solvent }\end{array}$ & 1.3 & 2.09 & 0.62 & 0.5979 \\
\hline $\begin{array}{l}\% \mathrm{~A} \text { in solvent } * \% \mathrm{~A} \text { in } \\
\text { solvent }\end{array}$ & 1.02 & 2.17 & 0.47 & 0.6832 \\
\hline $\begin{array}{l}\text { Particle size } * \text { particle } \\
\text { size } * \operatorname{coal} /(\mathrm{A}+\mathrm{B})\end{array}$ & 2.05 & 2.96 & 0.69 & 0.5602 \\
\hline $\begin{array}{l}\text { Particle size } * \text { coal } / \\
\quad(\mathrm{A}+\mathrm{B}) * \operatorname{coal} /(\mathrm{A}+\mathrm{B})\end{array}$ & 2.57 & 2.96 & 0.87 & 0.4761 \\
\hline $\begin{array}{l}\text { Particle size * particle } \\
\text { size } * \% \mathrm{~A} \text { in solvent }\end{array}$ & -1.47 & 2.96 & -0.50 & 0.6677 \\
\hline
\end{tabular}

\subsection{Regression analysis}

Minitab $^{\mathrm{TM}}$ (version 18) was used for the regression analysis. The quality of the multiple regression model fitting was measured by calculating the coefficient of regression $R^{2} . F$ test was used for testing its statistical significance. The analysis of variance test was used to calculate the significance of these linear parameters on the extraction yield. The results of which have been given in Table 12 . The results again predict the much higher effect of the particle size on the extraction yield with the least $p$ value and highest $F$ value (Segurola et al. 1999). Thus the regression analysis was found to be in conformity with the design of experiments methodology.

\subsection{Solvent recovery}

Solvent recovery was also noted during the course of these extraction studies and the amounts of NMP and EDA recovered are shown in Table 13. The high recovery (greater than 90\%) of NMP and EDA solvents in this process seems to be a step towards making the process economically attractive in future for the possibility of its use (Chandaliya et al. 2015). 

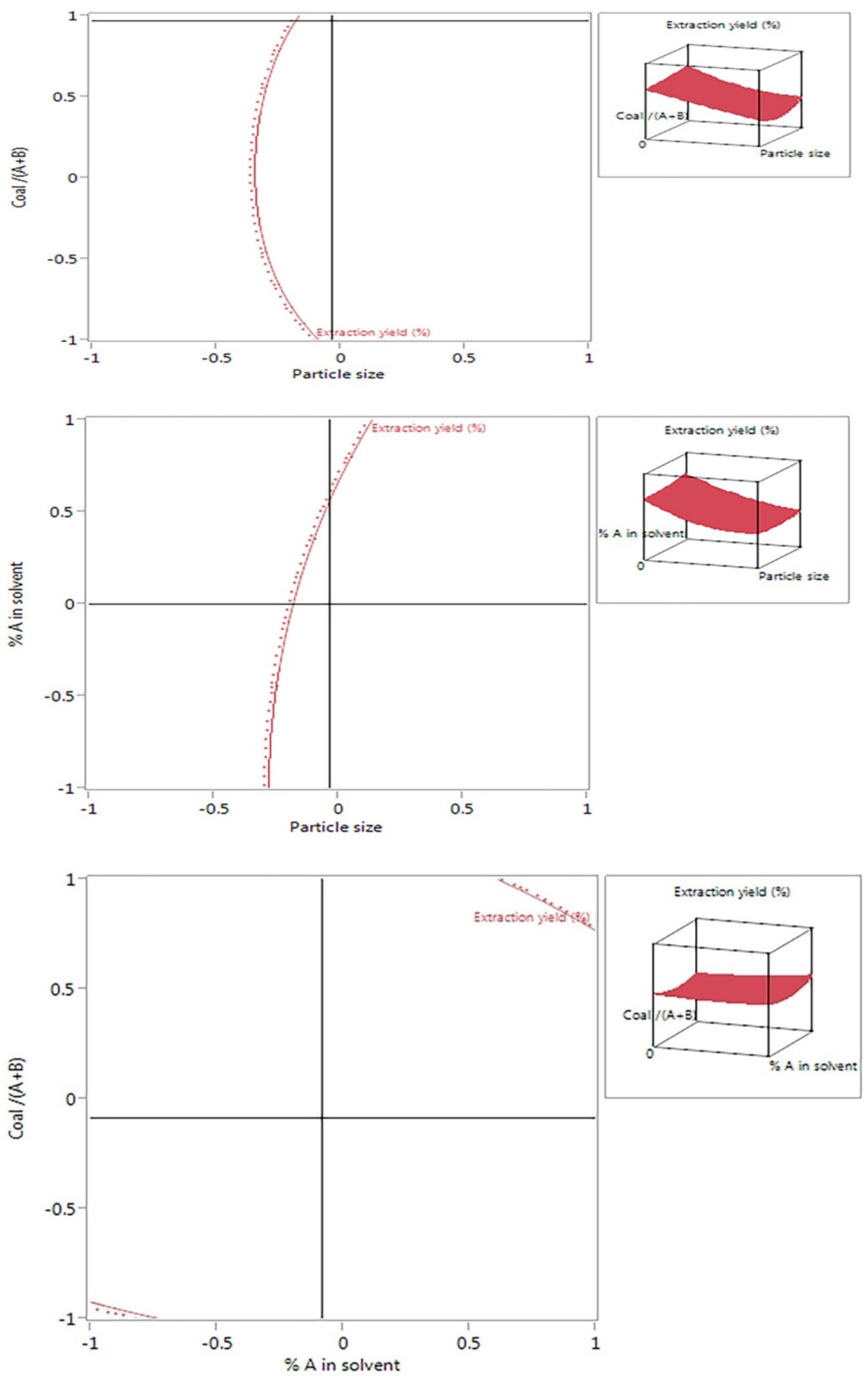

Fig. 6 Contour profilers for the parameters keeping one parameter constant and varying the other two [A: amount of co-solvent (EDA), A + B: total amount of co-solvent + solvent $(\mathrm{EDA}+\mathrm{NMP})]$ 


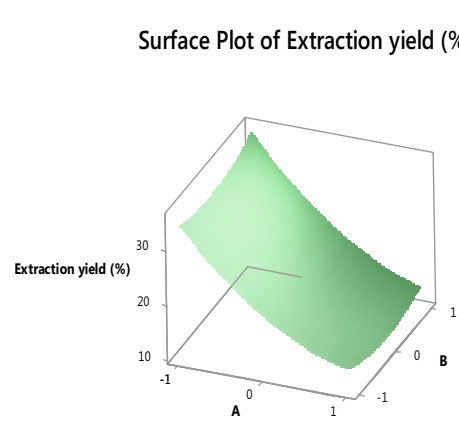

(a)

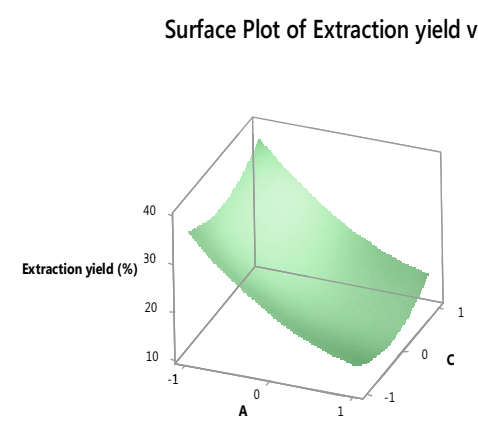

(b)

Surface Plot of Extraction yield (\%) vs C, B $\begin{gathered}\text { Hold Values } \\ \text { A } 0\end{gathered}$

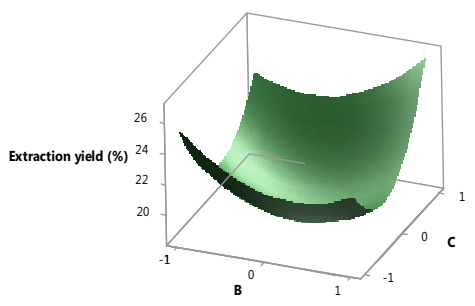

(c)

Fig. 7 Response surface plot showing the predicted values of the extraction yield with effect on particle size (A) and \% co-solvent in solvent (B) (a), particle size with coal/total amount of co-solvent + solvent $(\mathrm{C})(\mathbf{b})$ and \% co-solvent in solvent $(\mathrm{B})$ and coal/total amount of co-solvent + solvent $(\mathrm{C})(\mathbf{c})$ [A: amount of co-solvent (EDA), A + B: total amount of co-solvent + solvent $($ EDA + NMP)]

\section{Conclusions}

Solvent extraction of a high ash, low grade non-coking Indian coal, Kedla coal was performed using pre-treatment with acetic acid followed by extraction with NMP and EDA. Optimization of the extraction parameters was carried out. Using Definitive Screening Design for optimization of five parameters and RSM-Box Behnken experimental design for 3 parameters, maximum extraction yield under the given set of conditions was obtained. About
Table 12 Analysis of variance model regression on extraction yield

\begin{tabular}{lrrrrr}
\hline Source & DF & Adj SS & Adj MS & $F$ value & $p$ value \\
\hline Regression & 3 & 908.11 & 302.702 & 26.18 & 0.000 \\
Particle size & 1 & 905.25 & 905.251 & 78.30 & 0.000 \\
\%A in solvent & 1 & 0.21 & 0.211 & 0.02 & 0.895 \\
Coal/A + B & 1 & 2.64 & 2.645 & 0.23 & 0.642 \\
Error & 11 & 127.18 & 11.562 & & \\
Lack-of-fit & 9 & 92.14 & 10.237 & 0.58 & 0.766 \\
Pure error & 2 & 35.05 & 17.523 & & \\
Total & 14 & 1035.2 & & & \\
\hline
\end{tabular}

$R^{2}: 87.72 \%, R^{2}$ (adj.): $84.36 \%, R^{2}$ (pred.): $80.80 \%$

$\mathrm{DF}$, degree of freedom; SS, sum of squares; MS, mean of squares; F, $F$ value; $p$, significance

Level of $P$-value (a significance level $<0.05$ )

Table 13 Amount of solvents recovered during the extraction process

\begin{tabular}{lrr}
\hline Solvents used for extraction & NMP & EDA \\
\hline Amount of solvents used (\%) & 100.0 & 100.0 \\
Solvents recovered (\%) & 92.0 & 90.0 \\
Unaccounted loss (\%) & 8.0 & 10.0 \\
\hline
\end{tabular}

$39.5 \%$ of the extraction yield could be achieved with maximum desirability output for these parameters obtained using the design of experiments (DSD and RSM) technique i.e. the particle size less than 125 micron, co-solvent to solvent concentration (vol\%) of $15 \%$ of the total solvent concentration and the coal to solvent ratio as 1:20 (wt/vol). This technique also shows the linear and square interaction effects of the different parameters. The RSM model and the intercept values show the maximum impact of the coal particle size on the extraction yield. The regression analysis was found to be in good agreement with the RSM responses. This extraction process makes use of mild atmospheric pressure conditions unlike the high pressure and temperature conditions that make use of hydrogenating solvents where the clean coal product recovery is extremely difficult. Design of experiments reduces the number of experimental runs to be performed for optimization. The clean coal extraction yield is relatively high and this optimization consumes fewer amounts of the solvents. This technique results in leading to the conditions on obtaining enhanced amount of super clean coal without resorting to large number of experiments of process intensification studies on the organo-refining of power grade coal using the designer e, $\mathrm{N}$ solvent system. Organo-refining is an 
emerging clean coal technology and there is a need to make it economical. Present study is a step in this direction.

Acknowledgements The authors would like to thank NTPC Badarpur, New Delhi for arranging the coal sample for research work.

Open Access This article is distributed under the terms of the Creative Commons Attribution 4.0 International License (http://crea tivecommons.org/licenses/by/4.0/), which permits unrestricted use, distribution, and reproduction in any medium, provided you give appropriate credit to the original author(s) and the source, provide a link to the Creative Commons license, and indicate if changes were made.

\section{References}

Aslan N, Cebeci Y (2007) Application of Box-Behnken design and response surface methodology for modelling of some Turkish coals. Fuel 86:90-97. https://doi.org/10.1016/j.fuel.2006.06.010

Azimi E, Karimipour S, Rahman M, Szymanski J, Gupta R (2013) Evaluation of the performance of air dense medium fluidized bed (ADMFB) for low-ash coal beneficiation. Part 1: effect of operating conditions. Energy Fuels 27:5595-5606. https://doi. org/10.1021/ef400456n

Balakrishnan S, Midhun Reddy V, Nagarajan R (2015) Ultrasonic coal washing to leach alkali elements from coals. Ultrason Sonochem 27:235-240

Chandaliya VK, Banerjee PK, Biswas P (2012) Optimization of solvent extraction process parameters of Indian coal. Min Process Extr Metall Rev 33:246-259

Chandaliya VK, Biswas P, Banerjee PK (2015) Process for production of low ash clean coal from high ash coal with total solvent recovery. US20150007494 A1

Chen C, Gao J, Yan Y (1998) Role of noncovalent bonding in swelling of coal. Energy Fuels 12(6):1328-1334

Dryden IGC (1948) Extraction of bright coals by anhydrous ethylene diamine. Nature 162:959-960

Elliott MA (1981) Chemistry of coal utilization, second supplementary volume. Wiley, New York

Giri CC, Sharma DK (2000) Mass-transfer studies of solvent extraction of coals in N-methyl-2-pyrrolidone. Fuel 79(5):577-585

Gunaraj V, Murugan N (1999) Application of response surface methodology for predicting weld bead quality in submerged arc welding of pipes. J Mater Process Technol 88:266-275. https:// doi.org/10.1016/S0924-0136(98)00405-1

Haenel MW (1992) Recent progress in coal structure research. Fuel 71:1211-1223. https://doi.org/10.1016/0016-2361(92)90046-q

Hall PJ, Larsen JW (1993) Evidence for the formation of stable coal$\mathrm{N}$-methylpyrrolidinone and coal-pyridine gels. Energy Fuels 89:47-51

Hernández MR, Murcia CF, Gupta R, de Klerk A (2012) Solventcoal-mineral Interaction during solvent extraction of coal. Energy Fuels 26:6834-6842

Hu YH, Painter PC, Coleman MM, Butera RJ (1998) Ramifications of chain connectivity in hydrogen-bonded polymer solutions. Macromolecules 31:3394-3396. https://doi.org/10.1021/ Ma980248x

Iino M, Takanohashi T, Ohsuga H, Toda K (1988) Extraction of coals with $\mathrm{CS}_{2}$-N-methyl-2-pyrrolidinone mixed solvent at room temperature: effect of coal rank and synergism of the mixed solvent. Fuel 67:1639-1647. https://doi.org/10.1016/00162361(88)90208-6
Jain N, Sharma DK (2004) Biohydrometallurgy for nonsulfidic minerals-a review. Geomicrobiol J 21:135-144

Kihong K, Heechan C, Sihyun L, Myoungwook M, Deayang L (2016) Coal and solvent properties and their correlation with extraction yield under mild conditions. Korean $\mathrm{J}$ Chem Eng 33(7):2142-2159

Kincl M, Turk S, Vrečer F (2005) Application of experimental design methodology in development and optimization of drug release method. Int J Pharm 291:39-49. https://doi.org/10.1016/j. ijpharm.2004.07.041

Kirk RE, Othmer DF (2006) Encyclopedia of chemical technology. Wiley, Hoboken. http://as.wiley.com/WileyCDA/WileyTitle/pro ductCd-0471484970.html

Krevelen DW (1993) Coal-typology, physics, chemistry, constitution. Elsevier Science, Amsterdam

Kumar M, Patel SK (2008) Characteristics of Indian non-coking coals and iron ore reduction by their chars for directly reduced iron production. Miner Process Extr Metall Rev 29:258-273. https:// doi.org/10.1080/08827500801997902

Kwak JS (2005) Application of Taguchi and response surface methodologies for geometric error in surface grinding process. Int J Mach Tools Manuf 45:327-334. https://doi.org/10.1016/j. ijmachtools.2004.08.007

Larsen JW, Mohammadi M (1990) Structural changes in coals due to pyridine extraction. Energy Fuels 4:107-110. https://doi.org/10. 1021/ef00019a019

Larsen JW, Green TK, Kovac J (1985) The nature of the macromolecular network structure of bituminous coals. J Org Chem 50:4729-4735. https://doi.org/10.1021/jo00224a014

Li C, Takanohashi T, Yoshida T, Saito I, Aoki H, Mashimo K (2004) Effect of acid treatment on thermal extraction yield in ashless coal production. Fuel 83:727-732. https://doi.org/10.1016/j.fuel. 2003.06.002

Masaki K, Kashimura N, Takanohashi T, Sato S, Matsumura A, Saito I (2005) Effect of pre-treatment with carbonic acid on "HyperCoal" (ash-free coal) production from low-rank coals. Energy Fuels 19:2021-2025. https://doi.org/10.1021/ef050030t

Mathews JP, Burgess-Clifford C, Painter P (2015) Interactions of Illinois No. 6 bituminous coal with solvents: a review of solvent swelling and extraction literature. Energy Fuels 29:1279-1294

Meshram P, Purohit BK, Sinha MK, Sahu SK, Pandey BD (2015) Demineralization of low grade coal-a review. Renew Sustain Energy Rev 41:745-761

Mishra A (2009) Assessment of coal quality of some Indian coals. Mining Engineering

Mishra S, Sharma DK (1990) Solvent extraction and extractive disintegration of coal in anthracene oil. Fuel 69(11):1377-1380

Nishioka M, Larsen JW (1990) Association of aromatic structures in coals. Energy Fuels 4:100-106

Nyathi MS, Clifford CB, Schobert HH (2013) Characterization of graphitic materials prepared from different rank Pennsylvania anthracites. Fuel 114:244-250

Otake Y, Suuberg EM (1997) Temperature dependence of solvent swelling and diffusion processes in coals. Energy Fuels 11:1155-1164

Painter PC, Park Y, Sobkowiak M, Coleman MM (1990) Coal solubility and swelling. 2. Effect of hydrogen bonding on calculations of molecular weight from swelling measurements. Energy Fuels 4(4):384-393

Pande S, Sharma DK (2002) Ethylenediamine-assisted solvent extraction of coal in N-methyl-2-pyrrolidone: synergistic effect of ethylenediamine on extraction of coal in N-methyl-2-pyrrolidone. Energy Fuels 16:194-204

Rahman M, Pudasainee D, Gupta R (2017) Review on chemical upgrading of coal: production processes, potential applications and recent developments. Fuel Process Technol 158:35-56 
Renganathan K, Zondlo JV (1993) Non-destructive extraction mechanism of bituminous coals using K-IETBTL-2-PY1LR0LID0NE. Fuel Sci Technol Int 11:677-695

Renganathan K, Zondlo JW, Mintz EA, Kneisl P, Stiller AH (1988) Preparation of an ultra-low ash coal extract under mild conditions. Fuel Process Technol 18:273-278

Segurola J, Allen NS, Edge M, Mc Mahon A (1999) Design of eutectic photoinitiator blends for UV/visible curable acrylated printing inks and coatings. Prog Org Coat 37:23-37

Sharma DK, Giri CC (2016) $\mathrm{CO}_{2}$ Gasification reactivity and kinetics studies of raw coal, super clean coal and Residual coals obtained after organo-refining (solvent extraction). J Power Technol 96(3):701-157-701-169

Shibaoka M, Stephens JF, Russell NJ (1979) Microscopic observations of the swelling of a high-volatile bituminous coal in response to organic solvent. Fuel 58:515-522
Song C, Schobert HH (1993) Opportunities for developing specialty chemicals and advanced materials from coals. Fuel Process Technol 34:157-1596

Song C, Schobert HH (1996) Non-fuel uses of coals and synthesis of chemicals and materials. Fuel 75:724-736

Suuberg EM, Otake Y, Langner MJ, Leung KT, Milosavljevic I (1994) Coal macromolecular network structure analysis: solvent swelling thermodynamics and its implications. Energy Fuels $8(6): 1247-1262$

Takanohashi T, Iino M (1995) Investigation of associated structure of upper freeport coal by solvent swelling. Fuel 9(5):88-93

Takanohashi T, Yanagida T, Iino M, Mainwaring DM (1996) Extraction and swelling of low-rank coals with various solvents at room temperature. Energy Fuels 10:1128-1132. https://doi. org/10.1021/ef960033t 